\title{
Endoscopic retrograde cholangiopancreatography in situs inversus partialis
}

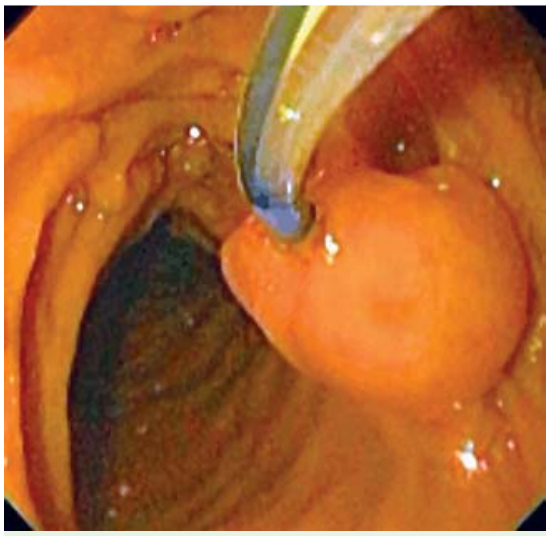

Fig. 1 Papilla oriented to the right side, at the 3 o'clock position.

Situs inversus viscerum is a rare autosomal recessive condition in which the organs are transposed to the opposite side. Two different conditions may be described: situs inversus totalis (with complete transposition of all viscera, abdominal and thoracic) or, more rarely, situs inversus partialis (SIP), with selective affection of one or several viscera [1]. We present the peculiar endoscopic and cholangiographic findings associated with SIP when endoscopic retrograde cholangiopancreatography (ERCP) was performed in a patient with choledocolithiasis.

An 88-year-old woman was admitted with abdominal pain at the epigastrium and left upper quadrant. The pain was associated with jaundice and fever $\left(37.8^{\circ} \mathrm{C}\right)$.

Abdominal ultrasound demonstrated transposition of liver and gallbladder to the left upper quadrant, and common bile duct dilated to $13 \mathrm{~mm}$. ERCP was performed and revealed distortion of gastric anatomy with inverted location of greater and lesser curves. The papilla was oriented to the right side at the 3 o'clock position ( Fig. 1). Sphincterotomy was performed, and purulent bile and thick sludge were cleared. Finally, a plain abdominal supine radiograph was taken ( $\bullet$ Fig. 2 ) and showed transposition of gallbladder

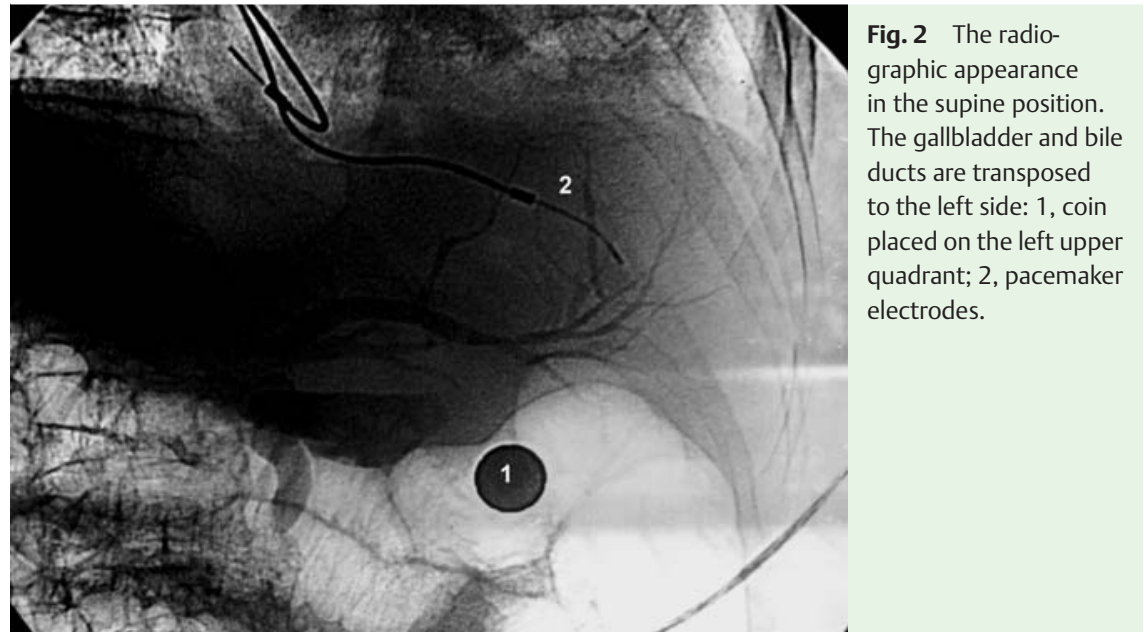

and bile ducts to the left side, as proved through the shadow of a coin ( $\bullet$ Fig. 2 , number 1) placed on the abdominal left upper quadrant and the normal location of pacemaker electrodes ( $\mathbf{F i g}$. 2, number 2 ). All of these findings were concordant with SIP.

ERCP in patients with anatomic variants or surgically altered gastrointestinal anatomy presents a challenge to the therapeutic endoscopist [2]. Transposition of the abdominal viscera associated with situs inversus, involves technical changes to the ERCP procedure $[3,4]$. In our case, the procedure was feasible with the patient in the usual prone position. However, the duodenoscope had to be turned $180^{\circ}$ clockwise in the stomach; moreover, a rotating sphincterotome was needed due to the ectopic orientation of the papilla. Despite these anatomical features and technical peculiarities, it was possible to carry out the procedure.

\section{Endoscopy_UCTN_Code_TTT_1AR_2AJ}

\section{C. de la Serna-Higuera, M. Perez-Miran- da, G. Flores-Cruz, P. Gil-Simón, A. Caro- Patón}

Department of Gastroenterology, Hospital Río Hortega, Valladolid, Spain

\section{References}

1 Claydon M, McLaughlin S. Gastrointestinal: situs inversus viscerum. J Gastroenterol Hepatol 2002; 17: 1329

2 Cheon YK, Fogel EL. ERCP topics. Endoscopy 2006; 38: 1092 - 1097

3 Venu RP, Geenen JE, Hogan WJ et al. ERCP and endoscopic sphincterotomy in patients with situs inversus. Gastrointestinal Endosc $1985 ; 31: 338-340$

4 Fiocca F, Donatelli G, Ceci Vet al. ERCP in total situs inversus viscerum. Case Rep Gastroenterol 2008; 2: 116-120

Bibliography

DOI 10.1055/s-0029-1214968

Endoscopy 2010; 42: E98

(c) Georg Thieme Verlag KG Stuttgart · New York . ISSN 0013-726X

\section{Corresponding author}

C. de la Serna Higuera, MD

Division of Gastrointestinal Endoscopy

Department of Gastroenterology

Hospital Río Hortega

C/Dulzaina $n^{\circ} 2$

Valladolid, 47012

Spain

Fax: +34-983-420400

csernah@hotmail.com 